\title{
NATURALEZA, PENSAMIENTO Y CULTURA EN EL JARDÍN CHINO. ANÁLISIS HOLÍSTICO DEL YUÁNYĔ
}

\section{NATURE, THOUGHT AND CULTURE IN THE CHI- NESE GARDEN. HOLISTIC ANALYSIS OF YUÁNYĚ}

\author{
Yingying $\mathrm{Xu}^{1}$ \\ José Manuel Almodóvar Melendo²
}

Recibido: 1 Diciembre 2019

Aceptado: 17 Marzo 2020

Resumen: En China existe una tradición milenaria de diseño de jardines que ha tenido como objetivo la búsqueda de integración con la naturaleza en armonía con ideas geománticas ancestrales. Durante la dinastía Míng (S.XIV-XVII) alcanzó su máximo explendor ya que constituyó un símbolo de prestigio social. En este contexto surgieron los primeros tratados sobre el jardín, siendo el más antiguo y completo el Yuányě, escrito en 1631 por Jì Chéng. En este artículo se realiza un análisis holístico del Yuányě con objeto de producir un relevante avance en la comprensión del jardín en relación a la cultura y el pensamiento chinos.

Palabras clave: jardín chino; Yuányě; taoísmo, budismo, confucianismo.

Abstract: There is a millenary tradition of garden design in China in a search for integration with nature in harmony with ancestral geomantic ideas. Garden design reached its maximum splendor during the Míng dynasty (14th-17th centuries) since it was a symbol of social prestige. In this context, the first treatises governing gardens appeared. The oldest and most complete is the Yuányě, written in 1631 by Jì Chéng. This article provides a holistic analysis of the Yuányě to produce a significant advance in understanding the garden in relation to Chinese culture and thought.

Key words: Chinese garden; Yuányě; taoism; buddhism; confucianism.

1. (xying@us.es) Profesora Asociada en el departamento de Filologías Integradas de la Universidad de Sevilla (USE).

2. (jmalmodovar@us.es) Profesor Titular en la ETS de Arquitectura y Grado en Estudios de Asia Oriental de la USE. 


\section{Introducción}

Los orígenes del jardín en China se remontan a más de tres mil años, siendo uno de los más antiguos del mundo. Aparece por primera vez durante la dinastía Shāng (S.XI a.C.), fue formulado a lo largo de las dinastías Wèi-jìn y Norte y Sur (S.III-VI), se desarrolla en la Táng (S.VII-X), madura durante la dinastía Sòng (S.X-XIII) y alcanza las cotas más altas de desarrollo en el período Míng (S.XIV-XVII).

Durante esta etapa de máximo desarrollo, políticos de alto rango, funcionarios y aristócratas rivalizaron en el diseño de jardines debido a que constituían un símbolo del nivel cultural y prestigio de sus propietarios. Como consecuencia, el número y la calidad de los jardines privados aumentó considerablemente, sobre todo en la próspera región de Jiāngnán. En esta zona situada al sureste del país residían la mayor parte de literatos y eruditos del país, y constituyó por tanto el centro cultural de China durante esa época.

En este contexto, surgieron numerosos artistas y obras maestras, algunas de las cuales han llegado hasta nuestros días y se han convertido en un importante referente artístico y cultural. Cabe destacar en este sentido, que nueve jardines de Jiāngnán han sido declarados Patrimonio Cultural de la Humanidad por la Unesco entre 1997 y 2000.

Por otro lado, aparecieron por primera vez tratados sobre el jardín que han proporcionado valiosas reflexiones y descripciones que ayudan a entender el arte del jardín en China. Entre ellos destaca el "Zhàngwù zhì" (Tratado de lo superfluo), escrito por Wén Zhènhēng entre 1620-1627. Este tratado se divide en doce volúmenes y se centra en la arquitectura del jardín y el diseño de interiores. Otro importante tratado es "Yījiā yán" (Opiniones de un hombre) de Liyuú, publicado en 1667. Uno de los volúmenes de esta obra trata sobre la arquitectura y la teoría del diseño de jardines. Sin embargo, el más completo y antiguo de todos es el Yuányě, escrito por el artista y pintor Jì Chéng en el año 1631. Se trata del primer tratado especializado en su totalidad en el diseño de jardines.

Aunque el Yuányě tuvo influencia entre algunos diseñadores y amantes de los jardines de la época, no alcanzó la repercusión que cabría esperar y permaneció durante más de tres siglos en el olvido. Posiblemente, la pérdida de prestigio e influencia de Ruán Dàchéng, mentor de Jì Chéng, frenó su divulgación. Este hecho pudo también ser debido a la inestabilidad social que se produjo a finales de la dinastía Míng como consecuencia de la invasión de las tribus Nüzhēn.

En 1921, el profesor Chén Zhí descubrió un ejemplar original del Yuányě guardado en la Universidad Imperial de Tokio, lo que supuso el inicio del largo camino de redescubrimiento e investigación de este 
tratado. Dos años después, se publicó por primera vez la versión completa del Yuányě en China, dentro de la Colección Xǐyǒngxuān de la editorial Táo Lánquán. Un año después fue reeditada por la editorial Zhū Qíqián. Sin embargo, la traducción al chino contemporáneo no se publicaría hasta 50 años después.

El estudio de los jardines en China ha pasado por tanto por diferentes etapas. El primer período englobaría el conjunto de experiencias acumuladas durante miles de años y transmitidas a través de escenas pictóricas o descripciones literarias. En una segunda etapa, aparecieron los primeros tratados o estudios estructurados sobre el jardín a finales de la dinastía Míng. Por último, ya en el Siglo XX, vuelven a realizarse estudios sistemáticos sobre el jardín que continúan hasta la actualidad.

A partir de los años 80, en el marco de la nueva apertura de China a occidente y su rápido proceso de transformación, surge un renovado interés por el arte del jardín. En lo que respecta al Yuányě, Chén Zhí (1981) publicó su primera traducción al chino contemporáneo con el título «Traducción anotada del Yuányě”. Se trata de un logro muy importante para el estudio de este transcendental tratado, ya que el estilo poético con el que fue escrito, conocido como piántǐ wén, dificulta ostensiblemente su comprensión. Debido a las ambigüedades que suscita el texto, Cáo Xùn ${ }^{3}$ publicó en 1984 un artículo con sugerencias sobre otras posibles interpretaciones ${ }^{4}$. Posteriormente, Chén Zhí ${ }^{5}$ realizó una segunda edición de su traducción en la que incluye nuevas notas aclaratorias y corrige algunas erratas. Esta última publicación ha sido el texto base utilizado en los posteriores estudios sobre el jardín tradicional chino, y la que se ha tenido como referencia principal para su traducción a idiomas extranjeros.

En occidente, el primer libro que menciona de forma extensa el Yuányě es "Gardens of China" de Osvald Siren ${ }^{6}$. Sin embargo, la traducción íntegra del Yuányě no se publicaría hasta finales de los 80 bajo el título "The Craft of Gardens, The Classic Chinese Text on Garden De-

3. Cáo, X.: Análisis e interpretación sobre las dudas en la 'Traducción Anotada del Yuányě' 《园冶注释释疑举析》[Yuányě zhùshì shìyí jǔxī]. Corpus de Historia y Teoría de Arquitectura 《建筑历史与理论》 [Jiànzhù lìshǐ yǔ lǐlùn]. Nánjīng: Editorial Popular de Jiangsu, 1984.

4. Cáo Xùn señala algunas posibles inexactitudes en el texto original. Por ejemplo, comenta que en lugar de 2.000 metros 四里 [sì lî] deberían ser 400 (pasos) 四百 [sì băi], lo que equivaldría aproximadamente a 667 metros. Teniendo en cuenta que el jardín sólo ocupaba una superficie de 5 mǔ 亩 $\left(3.333,5 \mathrm{~m}^{2}\right)$, el jardín no podría disponer del espacio suficiente para crear un recorrido tan largo.

5. Chén, Z.: Traducción Anotada del Yuányě 《园冶注释》[Yuányě zhùshì]. Běijīng: China Architecture \& Building Press, 1988.

6. Siren, O.: Gardens of China. New York: Ronald Press, 1949.

Thémata. Revista de Filosofía No61 (2020) pp.: 35-48. 
sign"7. Esta traducción de Alison Hardie con prólogo de Maggie Keswick contribuyó en gran medida a fomentar en occidente el interés por el arte del jardín en China. Unos años después, Che Bing Chiu publicó la segunda traducción del Yuányě a una lengua occidental, el francés ${ }^{8}$. Recientemente hemos realizado la primera traducción del chino al español ${ }^{9}$, con objeto de contribuir a la comprensión de las bases conceptuales del jardín en China a partir de la interpretación de sus fuentes originales.

Se trata de un tratado transcendental en el que se discuten ideas o principios de pensamiento creativo sobre los que se deben de inspirar las escenas del jardín. Así mismo, ofrece recomendaciones prácticas para la construcción de elementos arquitectónicos, aportando 235 ilustraciones que incluyen plantas de pabellones, tipos de ventanas y balaustradas, pavimentos y diseños decorativos de galerías o pasajes.

El Yuányě tiene también una gran relevancia cultural, ya que en China no han existido tradicionalmente especialistas en el diseño de jardines. Esta profesión era sustituida a menudo por literatos o pintores influenciados por diferentes corrientes de pensamiento, tales como confucianismo, budismo y taoísmo.

Aunque es una obra de suma importancia, su interpretación es muy compleja debido a que fue escrito en el estilo poético piántǐ wén. Como resultado, los conceptos a cerca del jardín son expresados de modo indirecto, en base a reflexiones a partir de las cuales es necesario visualizar y percibir sensaciones generadas por escenas o composiciones paisajísticas. Por otro lado, las ideas principales aparecen disgregadas de forma dispersa en diferentes capítulos y pasajes.

Para poder avanzar en la comprensión del Yuányě hemos considerado por tanto necesario la realización de un análisis transversal, desde diferentes perspectivas en relación a la cultura y el pensamiento chinos, en los que el entorno natural ha ocupado siempre un papel preponderante. De este modo, queremos aproximarnos al jardín desde su propia esencia o razón de ser, eludiendo filtros culturales que han provocado que sea a menudo estudiado desde la perspectiva occidental como algo curioso o exótico.

El concepto yijìng 意境 por ejemplo, es fundamental para comprender la composición de las escenas paisajísticas. Este término hace referencia a las imágenes y sentimientos que genera el paisaje en el espectador. Como el imaginario de la cultura popular china tiene una fuerte carga simbólica, resulta muy difícil entender desde occidente el mensaje subliminar

7. Hardie, A.: The Craft of Gardens, The Classic Chinese Text on Garden Design. New York: Better Link Press, 1988.

8. Che, C.: Yuányě. Le traité du jardin (1634). Besançon: Les éditions de l'Imprimeur, 1997.

9. Xu, Y. y Almodóvar, J. M.: La forja de los jardínes. Granada: Editorial Comares, 2019.

Thémata. Revista de Filosofía $\mathrm{N}^{\circ} 61$ (2020) pp.: 35-48. 
y las emociones que pretende transmitir una escena. En este sentido, la mera selección de las especies introducidas en el jardín lleva implícita una serie de ascepciones que transmiten una información relevante al observador. Por ejemplo, los granados están asociados a la fecundidad o el ideal chino de tener una familia muy extensa. Los melocotoneros y ciruelos no son considerados valiosos, pero muchas personas acuden a contemplarlos debido a sus hermosas flores. Se identifican por tanto con la sencillez y valores como sinceridad o fidelidad. En este sentido existe un proverbio chino que dice 'los melocotoneros y ciruelos no hablan, pero bajo ellos, se forman caminos' ${ }^{10}$.

En definitiva, queremos contribuir a desvelar los conceptos e ideas que subyacen en el Yuányě con una visión holística y desde su propia dinámica cultural, para de este modo arrojar nueva luz sobre las bases conceptuales sobre las que se fundamenta el diseño de jardines en China.

\section{Armonía entre el hombre y la naturaleza}

En el sustrato más básico de la cultura China subyace la creencia de que el hombre debe ocupar la naturaleza en armonía con el universo, entendido como un conjunto de dualidades o elementos opuestos que se complementan y entre los que se establece una diferente posición jerárquica ${ }^{11}$. La primera dualidad está constituida por el yīn y el yáng, situándose el yang por encima jerárquicamente del yin. Hacen referencia respectivamente a la puesta y salida del sol, oeste y este. Además de estas acepciones derivadas del movimiento del sol, los conceptos de yīn y yáng, se identifican con un gran número de aspectos o aplicaciones: femeninomasculino, noche-día, par-impar, sólido-vacío, etc. Aunque estos conceptos han sido mencionado en el "Yìjīng" o "Libro de los Cambios"12, fueron desarrollados por primera vez por Zhuāngzǐ, quien comentó: «el universo y yo hemos nacido al mismo tiempo, y todos los seres y yo somos uno y lo mismo.» ${ }^{13}$

Para conseguir una relación más íntima con la naturaleza, las construcciones en China han sido tradicionalmente muy simples y su tamaño ha estado regulado y limitado por normas preestablecidas. Los pa-

10. 桃李不言, 下自成蹊 (Trad. autores).

11. Almodóvar, J. M. y Cabeza, J. M.: "Environmental Features of Chinese Architectural Heritage: The Standardization of Form in the Pursuit of Equilibrium with Nature" en Sustainability $2443,2018$.

12. Wilhelm, H. y Baynes, C. F.: Change: Eight Lectures on the "I Ching". New York: Princeton University Press, 1960.

13. Preciado, I.: Zhuang Zi. Barcelona: Editorial Kairós, 1996, p. 48.

Thémata. Revista de Filosofía No61 (2020) pp.: 35-48. 
bellones del jardín representan lo sólido o las montañas, simbolizados por el yīn; mientras que el yáng ha sido identificado con al vacío ocupado por el jardín. Esta dualidad yīn-yáng o lleno-vacío ha condicionado la forma en la que los elementos arquitectónicos se han dispuesto en relación al jardín. Como el yáng está situado jerárquicamente por encima del yīn, el vacío ocupado por el jardín ha sido el elemento principal en torno al cual se han dispuesto las edificaciones siguiendo concepciones cosmológicas ancestrales, para de este modo estar en armonía con la naturaleza.

Estas creencias han sido recogidas tradicionalmente en teorías de geomancia o fēngshuǐ. Jì Chéng usa frecuentemente términos relacionados con estos conceptos y muestra un elevado conocimiento del fēngshuǐ. Por ejemplo, el término "Xiāngdi”" utilizado como título del primer capítulo, tiene dos significados según el "Diccionario de la Lengua China Xīnhuá"14. Uno está ligado a las características topográficas y de fertilidad del terreno, pero el otro hace referencia al análisis del lugar mediante el fēngshuǐ. Jì Chéng comenta en ese capítulo: «A la hora de aplicar las técnicas de geomancia para elegir la ubicación de los edificios del jardín, es aconsejable que estén cerca del agua». Así mismo, en el capítulo "Disposición" establece que «el primer elemento que hay que considerar son las vistas, siendo mejor si los edificios tienen orientación sur», lo cual coincide con las recomendaciones del fēngshuǐ. Sin embargo, cuando es necesario ponderar diferentes aspectos durante el proceso de diseño, Jì Chéng se muestra más libre a la hora de optar por la situación más adecuada en cada contexto. En concreto señala que "Cuando elegimos la orientación de los edificios, no debemos restringirnos a lo que dice el maestro de la geomancia». En definitiva, Jì Chéng poseía profundos conocimientos sobre el fēngshuǐ que se han visto reflejados en sus teorías sobre el diseño. Sin embargo, consideraba que su aplicación debía de ser adaptada a los requerimientos de cada situación específica.

\section{La naturaleza y el paisaje creado}

Jì Chéng considera que la finalidad del diseño está más relacionada con la percepción y el modo personal de interpretar la naturaleza que con reproducir de forma mimética elementos formales de paisajes existentes. Debemos tener en cuenta que el paisaje debía evocar sensaciones que activasen la conexión entre el hombre y la naturaleza, liberando los sentidos que nos hacen identificarnos con ella. Jì Chéng señala al respecto: «Cuando paseamos por donde nos llevan los pies, dudaremos que

14. Se ha utilizado el recurso [en línea]: “Diccionario de la Lengua China Xīnhuá” 《新华字 典》, http://xh.5156edu.com/html5/91151.html [Consultado: 27/11/2019].

Thémata. Revista de Filosofía $\mathrm{N}^{\circ} 61$ (2020) pp.: 35-48. 
este lugar tenga fronteras; y mientras levantamos la cabeza para mirar alrededor, nos inundará de emociones profundas». En el capítulo "Sobre el jardín” comenta también al respecto que «aunque el jardín sea construido artificialmente por el hombre, el resultado debe ser tan natural como si lo creara el cielo».

Es decir, el autor considera importante que el diseño del jardín consiga un equilibrio entre la intervención humana y su apariencia natural. Este concepto proviene de la cultura taoísta que considera que el hombre alcanza su sentido o razón de ser en su integración con la naturaleza, considerada jerárquicamente por encima del hombre ${ }^{15},{ }^{16}$.

Como consecuencia, Jì Chéng establece pautas a seguir en relación a la elección del terreno, disposición de elementos arquitectónicos, préstamos de paisajes, construcción de montañas artificiales e incluso la distribución de la vegetación para poder obtener un resultado natural. En concreto, en el capítulo "Ubicación" señala:

«Las mejores condiciones naturales para un jardín se encuentran entre las colinas con árboles, donde existan altos y hondonadas, zonas sinuosas y profundas, acantilados suspendidos y empinados, llanuras planas y amplias, este sitio poseerá sus propios encantos naturales sin necesidad de tratamiento humano».

El jardín debe por tanto adaptarse a la topografía del terreno e incluso potenciarlo en la medida de lo posible, ya que «debido a la naturaleza del terreno obtendremos jardines rectangulares, redondos, inclinados o curvos y no por ello hay que intentar modificarlos». En el apartado "Montañas artificiales" añade que «es preferible que estén encajadas libremente en armonía con el entorno a que presenten una disposición lineal intencionada». Este mismo concepto es repetido y enfatizado en arroyos y cascadas. Es decir, es partidario de evitar la simetría y la regularidad impuesta por el hombre, ya que «si entendemos el verdadero significado del paisaje real, cuando construyamos su imitación se convertirá en real». Jì Chéng considera por tanto que el arquitecto debe

15. Almodóvar, J. M. y Xu, Y.: "Habitar la naturaleza en armonía con el universo. Metafísica, geometría cósmica y orden social en la tradición arquitectónica china” en Araucaria 35, 2016, pp. 151-177.

16. Almodóvar, J. M. y Cabeza, J. M.: "Revitalizing environmental features of Japanese architecture. The experience of Raymond, Schindler and Neutra through their collaboration with Wright" en Architectural Science Review 61(6), 2018, pp. 500-515.

Thémata. Revista de Filosofía $\mathrm{N}^{\circ} 61$ (2020) pp.: 35-48. 
ser capaz de manifestar la esencia de la naturaleza en el jardín y provocar sensaciones que la conecten con el espectador.

\section{El concepto $Y i$ 宜 o "adecuado". Dicotomía entre objetivi- dad y subjetividad}

La mayoría de los jardines de Jiāngnán fueron construidos en el interior de ciudades, por lo que disponían de un espacio muy limitado para poder reproducir paisajes naturales. Como consecuencia, el método de "préstamo de paisajes" 17 fue necesario para ampliar la profundidad y amplitud del jardín utilizando el entorno como fondo paisajístico, para obtener de este modo una mayor percepción de integración con la naturaleza. Debemos tener en cuenta, que el concepto "préstamos de paisaje" no obedece sólo a lo físico sino que también hace referencia a experiencias subjetivas que pueda evocar el diseño.

Jì Chéng le dedica un capítulo completo a esta cuestión, e incluso enfatiza que «el préstamo de paisajes es la parte más importante en el diseño del jardín». En el capítulo "Teoría de la construcción” sintetiza este método en los siguientes términos:

«La esencia de la arquitectura del jardín se basa en el préstamo de paisajes según las características del terreno, y en la armonización de los diferentes elementos para crear una solución adecuada. Ni el constructor es capaz de hacerlo, ni el propietario del inmueble tiene control sobre ello. Es necesario contratar a una persona cualificada en dicha tarea para llevar a cabo la construcción y ahorrar dinero».

Jì Chéng identifica el concepto "adecuado" con el carácter Yí 宜, que hace referencia a la armonización de los diferentes elementos que componen el conjunto del jardín. Se trata del carácter más utilizado en el Yuányě, en concreto aparece en 74 ocasiones. Lo cual es un indicativo de la importancia que el autor le confiere a que el diseño sea "adecuado" en relación a los otros elementos para obtener un conjunto armonioso. Sin embargo, esta armonización obedece según Jì Chéng a una regla fija, sino que depende del criterio subjetivo del arquitecto ante los aspectos objetivos que condicionan al diseño. "Adecuado" hace alusión por tanto a que la relación entre lo objetivo y subjetivo está en armonía, constituyendo como toda dualidad una unicidad.

Para alcanzar este estado de armonía el autor insiste en una idea simple y lógica, pero que no se había explicitado anteriormente en China: «Cada jardín puede ser diferente, no hay un método fijo». En este

17. El concepto "préstamo de paisajes" hace referencia a utilizar o reproducir elementos, escenas o conceptos de unos paisajes en otros.

Thémata. Revista de Filosofía $\mathrm{N}^{\circ} 61$ (2020) pp.: 35-48. 
sentido comenta en el "Prefacio" que «el jardín debe de adaptarse a las diferentes circunstancias de cada persona, no puede ser concebido de otro modo [...] Los distintos tipos de terreno y entorno requieren tratamientos diferentes y adecuados y deben de ser sometidos por tanto a una cuidadosa consideración».

En relación a los criterios de diseño Jì Chéng comenta que: «no aplica las normas convencionales, sigue a su corazón», es decir, que no hay un método fijo. Sin embargo "seguir a su corazón"18 no significa que el arquitecto deba diseñar sin ningún criterio, sino que debe de tener destreza para saber captar lo más adecuado o conjugar un balance entre patrones o prácticas establecidas y la singularidad de cada caso específico con un sentido estético.

\section{La dualidad jardín-obra pictórica en la interpretación de la naturaleza}

En la tradición China siempre ha existido el deseo de reproducir magníficas montañas o hermosos paisajes acuáticos en un espacio propio. De hecho, el término tradicional para definir el concepto de paisaje es shānshur 山水, que significa literalmente montaña y agua. Sin embargo, reproducir estos elementos en un espacio limitado es muy complejo, por lo que se ha recurrido frecuentemente a técnicas de representación pictórica.

Como consecuencia, no ha habido muchos textos en China especializados en el diseño de jardines. Sin embargo, se han desarrollado teorías muy extensas sobre representación pictórica, en especial de paisajes. Las teorías sobre la pintura paisajística han sido en cierto modo compartidas con el arte del jardín ${ }^{19}$. De hecho, los métodos utilizados para el diseño de jardines coindicen en buena medida con conceptos pictóricos, y muchos célebres pintores han dominado simultáneamente el arte de construir jardines ${ }^{20}$.

En definitiva, el dominio de las técnicas pictóricas ha sido considerado una capacidad básica que debe poseer un buen diseñador de jardines. En este sentido, Jì Chéng comenta que:

18. El término corazón hace referencia en China al pensamiento o idea, ya que antiguamente se consideraba que el corazón era el órgano que pensaba. Por tanto, "seguir a su corazón" hace alusión en este contexto a que el diseñador debe seguir sus propias ideas o criterios en el diseño basándose en las condiciones objetivas del entorno. De este modo, el diseño diferirá en cada situación específica.

19. Péng, Y.: Análisis de los jardines clásicos chinos 《中国古典园林分析》[Zhōngguó gǔdiăn yuánlín fēnxī]. Běijīng: China Architecture \& Building Press 中国建 筑工业出版社, 1986.

20. Gěng, 1.: Jardines clásicos chinos 《中国古代园林》[Zhōngguó gǔdài yuánlín]. Běijīng: Commercial Press 商务印书馆, 1988.

Thémata. Revista de Filosofía No61 (2020) pp.: 35-48. 
«Cuando era joven, era conocido como pintor y debido a mi carácter, me gustaba explorar y buscar lugares insólitos. Me encantaban las pinturas de Guān Tóng y Jīng Hào, y emulaba frecuentemente sus estilos en mis obras».

Por otro lado, la pintura china se ha caracterizado por reproducir la naturaleza mediante una interpretación subjetiva del autor para captar su esencia. En este sentido Jì Chéng menciona en múltiples ocasiones la importancia del yijìng 意境 en la composición de las escenas paisajísticas del jardín. Se trata de un concepto que proviene originariamente del budismo y hace referencia a un estado de percepción superior alcanzado mediante la meditación. Yì 意 se identifica con la idea o concepción, con elementos subjetivos. Por el contrario, Jing 境 hace referencia a aspectos más objetivos del paisaje, pero no sólo a elementos físicos, sino también a estados emocionales. Podemos por tanto entender este concepto como las imágenes y sentimientos originados por el paisaje. Es decir, la escena no sólo contiene el paisaje físico, sino que también integra la experiencia del espectador en una sola unidad. Jì Chéng refleja esta idea en numerosos pasajes. Por ejemplo, en el capítulo "Préstamo de paisajes" comenta:

«Podremos disfrutar la tranquilidad de este lugar aislado y deleitarnos entre colinas y valles. De repente nuestros pensamientos viajan más allá del mundo de polvos ${ }^{21}$, y nos sentiremos como si estuviéramos paseando dentro de un cuadro».

\section{Relación del jardín con otras manifestaciones culturales. Literatura, poesía, música}

El estilo piántǐ wén utilizado por Jì Chéng en el Yuányě, dota al tratado de una narrativa poética de gran calidad e interés literario. Por otro lado, a lo largo del texto se hacen continuas referencias a obras literarias clásicas, tales como "Las Memorias Históricas" [Shǐjì] de Sīmă Qiān ${ }^{22}$. Incluye también expresiones procedentes de novelas y fábulas, entre las que podemos destacar "Un Nuevo Relato de los Cuentos del Mundo" [Shìshuō xīnyǔ] compilada y editada por Liú Yìqìng durante la dinastía del Sur. Las historias y alusiones procedentes de esta novela han sido utilizados frecuentemente en óperas y obras literarias.

21. El mundo de polvos (chénshi) es un término usado en el budismo y el taoismo, que hace referencia a la vanidad de la sociedad, al mundo de los humanos. También es conocido como polvo rojo (hóngchén).

22. Primer libro sobre historia en el que no se usa un método cronológico, sino que se narran los sucesos históricos a través de la biografía de personajes relevantes, principalmente políticos. Abarca más de 3000 años de historia, desde la época del Emperador Amarillo hasta el año 101 a.C. de la dinastía Xī Hàn.

Thémata. Revista de Filosofía No61 (2020) pp.: 35-48. 
La poesía es también un tema recurrente en el Yuányě. Jì Chéng expresa su fascinación por ella señalando que: «Un jardín lleno de poesías parecerá un paraíso». Existen numerosas alusiones a composiciones poéticas de diferentes épocas en el Yuányě. Entre ellas destacan la colección de poesías sobre escenas paisajísticas de Wăngchuān ${ }^{23}$ escrita por Wáng Wéi (701?-761d.C), o las célebres obras de Lǐ Bái (701-762), considerado como uno de los poetas más destacados de la historia de China.

El concepto yijing que hemos mencionado anteriormente puede ser también utilizado mediante composiciones poéticas. De hecho, las escenas paisajísticas responden a menudo a una recreación o interpretación de su yijjing poético. Un ejemplo muy representativo es la galería denominada, ¿Con quién me siento? Fue construía para alcanzar la emoción descrita en el siguiente poema de Sū Shì (1037-1101 d.C.):

"Me siento en la butaca para descansar, y contemplo desde la ventana de la Torre Yǔgōng, los picos de montaña como si fueran miles de flores abriéndose. ¿Con quién me siento para compartir este hermoso paisaje? La luna, la brisa y yo."

Jì Chéng también hace referencia a la música a lo largo del tratado. Considera que los sonidos naturales pueden ser tan bellos como la música mejor interpretada y recrea de forma poética sonidos del paisaje. Por ejemplo, en "Préstamo de paisajes" señala: «En verano, entre la sombra de los bosques las oropéndolas cantan; en las sinuosas montañas se oye repentinamente el canto de un leñador».

Así mismo, en el capítulo "Sobre Yuányě", Ruán Dàchéng expresa cómo sería su vida ideal en un jardín del siguiente modo: «un lugar donde poder leer y tocar el laúd. Durante los días festivos [...] para contemplar danzas en el jardín. Imitando a Lăo Láizi, podría vestirme con ropa de colores, cantar la canción de los ermitaños».

\section{El jardín y las principales corrientes de pensamiento en China}

En términos generales podemos considerar que la cultura tradicional china ha estado influenciada por tres doctrinas principales: confucianismo, budismo y taoísmo. El núcleo de la cultura confuciana recae en los valores éticos de una rígida estructura social, mientras que las otras dos tienen un carácter más religioso. Cada una de ellas ha ejercido de manera

23. Wăngchuān es la finca del famoso poeta y pintor Wáng Wéi, situada en el condado Lántián de la provincia de Shănxī. Como Wáng Wéi era un devoto budista, tras la muerte de su madre cambia el título de esta finca por el de Templo Wăngchuān.

Thémata. Revista de Filosofía No61 (2020) pp.: 35-48. 
distinta su influencia en los jardines clásicos. En este apartado discutiremos el modo en que han sido reflejadas en el Yuányě.

\subsection{Confucianismo}

El confucianismo ha tenido una gran repercusión en el ámbito de la arquitectura, principalmente en lo que respecta al orden espacial. Sin embargo, su influencia en el diseño de jardines es más limitada, debido a que no requieren un orden espacial estricto ${ }^{24}$.

Uno de los conceptos confucianos más importantes que ha ejercido influencia en los jardines es el de "moralidad metafórica" o břdé. Consiste en identificar virtudes de elementos de la naturaleza con la de los seres humanos, para simbolizar de este modo su noble espíritu. Podemos ver reflejado esta idea en una de las citas más famosas de las Analectas de Confucio (Período de Primaveras y Otoños, entre 722 - 481 a. C.) : «las personas inteligentes son sensatas, sus pensamientos son rápidos y ágiles como el flujo del agua, y las personas benevolentes son tranquilas y tolerantes, y sus temperamentos son como las firmes montañas».

Jì Chéng hace referencia a este concepto a lo largo del Yuányě. En concreto comenta en un pasaje, que «los caminos deberían estar alineados a los tres amigos auspiciosos, para que de este modo perduren mucho tiempo». Los tres amigos auspiciosos han sido identificados en la cultura popular con ciruelos, bambúes y piedras, que simbolizan respectivamente la valentía, firmeza y belleza interior. Podemos deducir por tanto que los amigos que invitamos a nuestro jardín deberían tener esas cualidades para que perdure la reputación del jardín.

Aunque la influencia del confucianismo en la composición artística de los jardines no es demasiado explícita, las connotaciones éticas de este modo de pensamiento han influido en que el jardín haya sido entendido como un lugar para cultivar las virtudes humanas. Resulta por tanto difícil definir qué elementos específicos del jardín han sido influenciados por el confucianismo.

\subsection{Budismo}

El budismo llegó a China durante la dinastía Dōnghàn (25-220) y posteriormente se integró con el taoísmo y el confucianismo, adquiriendo características propiamente chinas. La corriente budista Chán, también

24. Zhāng, F.: "Análisis del pensamiento filosófico sobre el arte de los jardines clásicos chinos”《浅析中国古典园林艺术中的哲学思想》[Qiănxī zhōngguó gǔdiăn yuánlín yìshù zhōng de zhéxué sīxiăng], Science \& Technology association forum 华中建筑 2: 164-165, 2007.

Thémata. Revista de Filosofía $\mathrm{N}^{\circ} 61$ (2020) pp.: 35-48. 
conocida como budismo Zen, busca trascender el mundo terrenal para alcanzar un estado de tranquilidad espiritual. Defiende el concepto "Buda y yo somos lo mismo", es decir sentirse como Buda consiste en alcanzar un nivel de percepción superior o wù mediante la meditación. Este objetivo se consigue frecuentemente mediante la contemplación de la naturaleza o el paisaje. Como consecuencia, en China surgieron los denominados jardines templarios, que albergan espacios para realizar actividades religiosas, así como funciones recreativas y de contemplación o meditación.

En el Yuányě podemos encontrar continuas alusiones a la cultura budista. Por ejemplo, en el capítulo "Sobre el jardín” se comenta: «Las pagodas deberían aparecer tenuemente a través de ventanas redondas, como en las maravillosas pinturas del joven general Ľ̌l». Jì Chéng utiliza el término chà 刹 para referirse a las pagodas. Chà es la abreviatura de la palabra sánscrita 刹多罗 en su traducción al chino, y es un término genérico utilizado para referirse a los monasterios budistas o templos. En otro pasaje Jì Chéng señala que: «así llegarían a menudo a nuestros oídos los cánticos sánscritos de los budistas».

Podemos observar que el autor utiliza préstamos visuales y acústicos del budismo. Este método de diseño no sólo aumenta la belleza paisajística del jardín, sino también imprime una determinada percepción psicológica. Cuando paseamos por el jardín, observamos vagamente a lo lejos templos budistas y escuchamos sus cánticos, sentimos estar sumergidos en un mundo contemplativo y haber encontrado la paz interior. También nos impulsa a reflexionar sobre la cultura budista, su forma de entender la existencia, la relación entre el hombre y la naturaleza etc.

Por otro lado, Jì Chéng incorpora objetos simbólicos del budismo en el diseño de elementos arquitectónicos del jardín. Por ejemplo, en el capítulo "Diagramas de puertas y ventanas", menciona tres diseños que son adecuados para santuarios budistas: pétalos de loto, rúyi ${ }^{25}$ y hoja de palma de Ceilán ${ }^{26}$. El loto y rúyì han sido asociados con la buena suerte

25. Rúyì es un objeto de artesanía tradicional concebido inicialmente como rascador para la espalda, que presenta un mango y cabezal con forma de nube. Durante la llegada del budismo, pasó a ser un símbolo de esta religión, y ha sido frecuentemente representado en estatuas de budas como símbolo de buena suerte. Con el tiempo fue perdiendo su sentido funcional y ha acabado convirtiéndose en un objeto decorativo.

26. La palma de Ceilán (Corypha umbraculifera) es una especie de palma nativa de África que ha sido cultivada extensamente en el sureste de India, China, Myanmar y Sri Lanka. Sus hojas han sido utilizadas para la escritura, sobre todo para textos sagrados budistas.

Thémata. Revista de Filosofía No61 (2020) pp.: 35-48. 
en el budismo, mientras que las hojas de palma de Ceilán eran utilizadas para copiar textos sagrados budistas.

\subsection{Taoísmo}

El taoísmo es una religión autóctona de China. Su fundador, Lăozǐ comenta en el "Dàodé Jīng": "Hay en el universo cuatro grandes, y el hombre se halla entre ellos. El hombre tiene por norma la tierra, la tierra tiene por norma el cielo, el cielo tiene por norma el curso, el curso tiene por norma a sí mismo». ${ }^{27}$

El curso o camino es el Tao, la madre de todos los seres vivos, la norma del hombre, del cielo y de la tierra. El Tao se tiene como norma a sí mismo. El concepto "a sí mismo" es la traducción literal del término zìrán, que significa espontaneidad o naturalidad, lo que implica una aceptación de la realidad tal y como es.

Podemos entender por tanto que el taoísmo entiende la existencia desde la relación entre el hombre y la naturaleza. Por tanto, el conocimiento del origen de las cosas es esencial para alcanzar la percepción del $\mathrm{Tao}^{28}$. Debido a esta estrecha relación con la naturaleza, las artes taoístas han influido en el fēngshư̌ ${ }^{29}$.

Las ideas defendidas por el maestro Lăozĭ coinciden en gran medida con conceptos sobre la armonía entre el hombre y la naturaleza defendidos por Zhuāngž̀, que se corresponde así mismo con un aspecto clave sobre el diseño de jardines tal y como hemos mencionado anteriormente.

Por otro lado, el taoísmo está relacionada con ideas chamánicas ancestrales $^{30}$ que incluyen la creencia en la inmortalidad. Como consecuencia, Jì Chéng alude a leyendas taoístas para explicar el estilo de vida anhelado en el jardín. En concreto señala: «Saber encontrar el relax, es la felicidad; saber disfrutar de la vida, es ser un inmortal». Jì Chéng muestra el verdadero valor de los jardines mediante su comparación con lugares donde existe idílicamente la inmortalidad.

El autor también emplea leyendas taoístas para ilustrar conceptos sobre el diseño de jardines. Por ejemplo, en el capítulo "Elementos decorativos" comenta: «A través de las aberturas de las paredes de

27. Suárez, A.: Tao te king. Madrid: Editorial Siruela, 2009, p. 79.

28. Ľ̌, J.: "Confucianism Taoism Buddhism and the generating of chinese classical garden art spirit”《儒道释哲学思想与中国古典园林艺术精神之生成》[Rúdàoshì zhéxué sīxiăng yǔ zhōngguó gǔdiăn yuánlín yìshù jīngshén zhī shēngchéng] en Journal of Hefei University of technology (social sciences) 合肥工业大学学报 22 (3), 2008, pp. 160-164.

29. Cabeza, J. M.: El Dao de la arquitectura. Granada: Editorial Comares, 2011.

30. En China existe una tradición chamánica denominada wuismo que está conectada con culturas neolíticas tales como la Hóngshān.

Thémata. Revista de Filosofía No 61 (2020) pp.: 35-48. 
madera podremos asomarnos implícitamente al paisaje del otro mundo». El concepto "otro mundo" hace referencia al de los inmortales. Jì Chéng usa esta alusión al taoísmo para revelarnos una norma importante en la composición del jardín, según la cual, el paisaje debe estar distribuido ingeniosamente de forma que podamos descubrirlo de manera sorpresiva o inesperada.

Al igual que en el caso de la cultura budista, Jì Chéng también introduce en el Yuányě referencias taoístas. Por ejemplo, comenta que: "Con las nieblas violetas de la mañana y las nubes azuladas del anochecer, el canto de las grullas llegará a nuestra almohada». Las nieblas violetas y las nubes azuladas se producen según la cultura popular en lugares donde hay inmortales. Por otro lado, la grulla es el símbolo taoísta de la inmortalidad.

En definitiva, Jì Chéng utiliza el atractivo que despierta el mundo de los inmortales en los seres humanos, realizando alusiones y metáforas al mismo para describir composiciones paisajísticas que contienen valores espirituales ampliamente integrados en la cultura china.

\section{Conclusiones}

El Yuányě es un tratado difícil de entender por su estilo literario, lo cual ha dificultado ostensiblemente su difusión. Jì Chéng utiliza el estilo piántǐ wén, caracterizado por el uso frecuente de composiciones rítmicas y poéticas. Sin embargo, esta circunstancia añade un componente estético a su contenido y ayuda al lector a percibir las sensaciones provocadas por el paisaje, pero dificulta que sus teorías sobre el diseño sean expresadas de forma directa o explícita. En este sentido, Zhèng Yuánxūn comenta en el prefacio del Yuányě que «en él sólo se describen un conjunto de reglas, que es como decir, que no se transmite nada. Sin embargo, estas reglas podrán ser aplicadas de forma flexible, con libertad, pero sin obviar sus principios».

Jì Chéng no aporta por tanto recomendaciones específicas sobre el diseño de jardines, lo cual sería en cualquier caso poco pertinente, ya que el diseño de jardines era considerado algo tan individual como el modo de experimentar el paisaje. De hecho, sólo se concretizan de forma ocasional las normas de construcción de edificaciones y de levantamiento de montañas.

Los conceptos de diseño son expuestos de forma transversal a lo largo del tratado, y en general se centran en el proceso de creación o en el resultado del mismo. Las pautas de diseño van encaminadas a usar adecuadamente las condiciones específicas de cada jardín, potenciar su singularidad y utilizar los paisajes del entorno como elementos propios

Thémata. Revista de Filosofía Nº1 (2020) pp.: 35-48. 
del jardín. Por el contrario, el resultado está relacionado con la obtención de una adecuada integración con el entorno, apariencia natural, relación con representaciones pictóricas y evocar determinadas sensaciones al espectador.

Por otro lado, Jì Chéng utiliza expresiones tales como "tierra de los inmortales", "mundo de polvos", así como otro tipo de alusiones que sugieren la relación del Yuányě con las principales corrientes del pensamiento chino, tales como la conducta social reflejada en la ética confuciana, los anhelos por la naturaleza del taoísmo, o reflexiones sobre el aislamiento o la vida contemplativa del budismo. De este modo, busca establecer una armonía entre el hombre y la naturaleza que es considerada como sinónimo de felicidad, plenitud y paz interior.

Debemos tener en cuenta que la forma de entender la relación del hombre con su entorno natural ha sido muy diferente en China y en occidente. Hablando en términos generales, en occidente se ha tendido a realizar una domesticación y organización de los elementos de la naturaleza de forma ajena a su propia esencia. Por el contrario, el jardín ha actuado en China como un elemento vertebrador de los patrones arquitectónicos y urbanos, que han favorecido por tanto una mayor integración del hombre con la naturaleza. Este énfasis en el jardín como elemento articulador de la composición y la necesidad de adaptarlo a su entorno natural está despertando un gran interés en paisajistas contemporáneos y conecta directamente con la nueva conciencia ecológica surgida en occidente.

En definitiva, el jardín chino es una manifestación cultural muy compleja que integra ideas o creencias ancestrales con la pintura, la literatura y otras artes en una búsqueda común de armonía y equilibrio con la naturaleza. El análisis del Yuányě desde una perspectiva holística puede contribuir a realizar un relevante avance en la comprensión de sus bases conceptuales. En este sentido, Zhèng Yuánxūn comenta en el prefacio de esta trascendental obra que «se convertirá en un modelo a imitar por futuras generaciones. ¿Quién puede afirmar que este libro no se convertirá en una obra de culto como el "Registro de los Artífices" [Kăo gōng jì] ${ }^{31}$ ?».

\section{Referencias bibliográficas}

Almodóvar, J. M. y Xu, Y.: "Habitar la naturaleza en armonía con el universo. Metafísica, geometría cósmica y orden social en la tradición arquitectónica china” en Araucaria 35, 2016, pp. 151-177. Almodóvar, J. M. y Cabeza, J. M.: "Environmental Features of Chinese

31. Libro clásico sobre ciencia y tecnología compilado a finales del período de Primavera y Otoño (aproximadamente 771 a 476 a. C.).

Thémata. Revista de Filosofía $\mathrm{N}^{\circ} 61$ (2020) pp.: 35-48. 
Architectural Heritage: The Standardization of Form in the Pursuit of Equilibrium with Nature" en Sustainability 2443, 2018.

Almodóvar, J. M. y Cabeza, J. M.: "Revitalizing environmental features of Japanese architecture. The experience of Raymond, Schindler and Neutra through their collaboration with Wright" en Architectural Science Review 61(6), 2018, pp. 500-515.

Cabeza, J. M.: El Dao de la arquitectura. Granada: Editorial Comares, 2011.

Cáo, X.: Análisis e interpretación sobre las dudas en la 'Traducción Anotada del Yuányě 《园冶注释释疑举析》 [Yuányě zhùshì shìyí jǔxī]. Corpus de Historia y Teoría de Arquitectura 《建筑历史与理论》[Jiànzhù lìshǐ yǔ lǐlùn]. Nánjīng: Editorial Popular de Jiangsu, 1984.

Che, C.: Yuányě. Le traité du jardin (1634). Besançon: Les éditions de l'Imprimeur, 1997.

Chén, Z.: Traducción Anotada del Yuányě 《园治注释》[Yuányě zhùshì]. Běijīng: China Architecture \& Building Press, 1988.

Gěng, l.: Jardines clásicos chinos 《中国古代园林》[Zhōngguó gǔdài yuánlín]. Běijīng: Commercial Press 商务印书馆, 1988.

Hardie, A.: The Craft of Gardens, The Classic Chinese Text on Garden Design. New York: Better Link Press, 1988.

Ľ̌, J.: "El confucianismo, el taoísmo, el budismo y la generación del espíritu del arte del jardín clásico chino”《儒道释哲学思想与中国 古典园林艺术精神之生成》 [Rúdàoshì zhéxué sīxiăng yǔ zhōngguó gǔdiăn yuánlín yìshù jīngshén zhī shēngchéng] en Journal of Hefei University of technology (social sciences) 合肥工业大学学报 22 (3), 2008, pp. 160-164.

Péng, Y.: Análisis de los jardines clásicos chinos 《中国古典园林分析》 [Zhōngguó gǔdiăn yuánlín fēnxī]. Běijīng: China Architecture \& Building Press 中国建 筑工业出版社, 1986.

Preciado, I.: Zhuang Zi. Barcelona: Editorial Kairós, 1996.

Siren, O.: Gardens of China. New York: Ronald Press, 1949.

Suárez, A.: Tao te king. Madrid: Editorial Siruela, 2009.

Xu, Y. y Almodóvar, J. M.: La forja de los jardínes. Granada: Editorial Comares, 2019.

Wilhelm, H. y Baynes, C. F.: Change: Eight Lectures on the "I Ching”. New York: Princeton University Press, 1960.

Zhāng, F.: "Análisis del pensamiento filosófico sobre el arte de los jardines clásicos chinos”《浅析中国古典园林艺术中的哲学思想》[Qiănxī zhōngguó gǔdiăn yuánlín yìshù zhōng de zhéxué sīxiăng], Science \& Technology association forum 华中建筑 2: 164-165, 2007. 



\section{TRADUCCIONES}


